\title{
The effect of neoadjuvant therapy on the 5-fluorouracil metabolic and relative enzymes of oral squamous cell carcinoma
}

\author{
TOMOMI YAMASHITA, MAKOTO TOIDA, KEIZO KATO, NGUYEN KHANH LONG, \\ YASUO MIYAZAKI, YUICHIRO ASAKA, DAIJIRO HATAKEYAMA, KAZUHIRO YONEMOTO, \\ HIROKI MAKITA, YUKIHIRO KATO and TOSHIYUKI SHIBATA
}

Department of Oral and Maxillofacial Surgery, Graduate School of Medicine, Gifu University, Gifu 501-1194, Japan

Received February 5, 2009; Accepted May 5, 2009

DOI: 10.3892/or_00000463

\begin{abstract}
To assess the effect of neoadjuvant therapy using tegafur/uracil (UFT) and radiation therapy on the 5-fluorouracil (5-FU) metabolic and relative enzymes, thymidylate synthase (TS), dihydropyrimidine dehydrogenase (DPD), orotate phosphoribosyl transferase (OPRT) and thymidine phosphorylase (TP) in oral squamous cell carcinoma (OSCC), we examined the mRNA expression and immunohistochemical staining status of these enzymes using 17 surgical specimens. Seven patients did not receive any neoadjuvant therapy and 10 were treated with UFT and local irradiation therapy. Our result showed that the mRNA expression of these enzymes in neoadjuvant group was not significantly different from that of non-treated group using real-time quantitative PCR. To confirm the protein expression, we also carried out immunohistological staining of TS and DPD two key enzymes in the 5-FU metabolism, using the same specimens. Immunohistological staining status did not correspond to the results of mRNA analysis completely, though no significant difference between the groups was observed. Furthermore, no significant relationship between the UFT administration period and mRNA expression of the 5-FU metabolic enzymes was observed in neoadjuvant therapy group and also the distribution of the enzyme mRNA expression levels was similar to that of non-treated group. The results suggested that the neoadjuvant therapy of OSCC might not affect the expression status of 5-FU metabolic and relative enzymes in surgical tumor samples and the tumor tissues might serve as a useful specimen source
\end{abstract}

Correspondence to: Dr Tomomi Yamashita, Department of Oral and Maxillofacial Surgery, Graduate School of Medicine, Gifu University, 1-1 Yanagido, Gifu 501-1194, Japan

E-mail: yamatomo@gifu-u.ac.jp

Abbreviations: OSCC, oral squamous cell carcinoma; TS, thymidylate synthase; DPD, dihydropyrimidine dehydrogenase; OPRT, orotate phosphoribosyl transferase; TP, thymidine phosphorylase; 5-FU, 5-fluorouracil; UFT, tegafur/uracil; RT, radiation therapy

Key words: neoadjuvant therapy, 5-fluorouracil metabolic enzymes, oral squamous cell carcinoma to analyze the expression status of the 5-FU metabolic and relative enzymes and to determine the prospective efficiency of 5-FU-based adjuvant chemotherapy.

\section{Introduction}

5-Fluorouracil (5-FU) is a widely used anti-cancer agent for the therapy of a variety of malignancies including gastrointestinal, mammary non-small cell lung and head and neck cancers. Especially, tegafur/uracil (UFT) as an oral 5-FU prodrug is commonly used for adjuvant and/or neoadjuvant therapy of these cancers. Previously, the relationship between 5-FU metabolic and relative enzymes in cancers including oral squamous cell carcinoma (OSCC) and the anti-cancer effect of 5-FU has been reported and evaluation of the enzyme expression can be used to predict the desirable efficiency of 5-FU-based chemotherapy prospectively (1-5). However, the effect of the neoadjuvant therapy using 5-FU and irradiation on the 5-FU metabolic and relative enzymes is controversial and remains unclear (6-9). Furthermore, there is no comparative study of that in head and neck cancer. In this study, to clarify the effect of the neoadjuvant therapy, particularly 5-FU administration, on 5-FU metabolic and relative enzymes, we investigated the expression status of these enzymes in oral squamous cell carcinoma tissues of patients treated with neoadjuvant therapy and non-treated group.

\section{Materials and methods}

Patient population. A total of 17 patients who underwent surgical resection of primary OSCC at the Department of Oral and Maxillofacial Surgery, Gifu University Hospital between March 2002 and August 2003 was included in this study (Table I). Six patients were male and 11 were female with average age was 67.4 years. Ten patients received neoadjuvant therapy of perioral 5-FU administration and local irradiation. In neoadjuvant group, the average amount of UFT was $14500 \mathrm{mg}$ (2000-25200 mg) and the average doses of external beam radiation (RT) was $32 \mathrm{~Gy}$ (range 30-40 Gy).

This study was approved by the Institutional Review Board of Gifu University. Agreements of all participating patients were obtained using the written informed consent document.

RNA extraction and cDNA synthesis. One tissue specimen about $3 \mathrm{mg}$ of weight and $3 \mathrm{~mm}$ in length were obtained from 
operation materials. Following surgery, the tissue samples were immediately frozen in liquid nitrogen and stored at $-80^{\circ} \mathrm{C}$ until use. The interval between operation and freezing process was done as quick as possible.

Total RNA was isolated using an RNeasy mini kit (Qiagen, Inc., Chatsworth, CA) and DNase treatment was performed using the RNase-Free DNase set (Qiagen, Inc.) according to the manufacturer's instruction. After RNA isolation, cDNA was prepared from each sample using Super Script II Reverse Transcriptase (Invitrogen Co., Carlsbad, CA). Reverse transcription with up to $4 \mu \mathrm{g}$ of total RNA was carried out in a total volume of $1 \mu \mathrm{l}$ containing $500 \mu \mathrm{g} / \mathrm{ml}$ of oligo (dT), in $250 \mathrm{mM}$ Tris- $\mathrm{HCl}$ (pH 8.3), 375 mM KCl, 15 mM MgCl $2,0.1$ M DTT and $1 \mu \mathrm{ldNTPs}$. Initially, the total RNA solution mixed with oligo (dT) was heated at $65^{\circ} \mathrm{C}$ for $5 \mathrm{~min}$ and immediately chilled on ice, then the other reagents were added. First-strand cDNAs were obtained and dissolved in $20 \mu 1$ distilled water.

Real-time quantitative RT-PCR assay. The mRNA levels of TS, DPD, OPRT and TP were evaluated by real-time quantitative RT-PCR (TaqMan PCR) using an ABI Prism 7700 sequence detector (Perkin-Elmer Applied Biosystems, Foster City, CA). The $B$-actin gene was used as the endogenous control gene. Primers and TaqMan probes for each gene were designed based on the nucleotide sequence of human TS, DPD, OPRT and TP (Table II). The PCR mixture contained $10 \mu \mathrm{l}$ of each appropriately diluted cDNA sample (standard curve points and patient samples), $200 \mathrm{nM}$ forward primer, $200 \mathrm{nM}$ reverse primer, $100 \mathrm{nM}$ TaqMan probe and 12.5 $\mu \mathrm{l}$ TaqMan Universal PCR Master Mix (Perkin-Elmer Applied Biosystems), in a final volume of $25 \mu \mathrm{l}$. The PCR profile consisted of one incubation at $94^{\circ} \mathrm{C}$ for $2 \mathrm{~min}$, one incubation at $95^{\circ} \mathrm{C}$ for $10 \mathrm{~min}$ and 40 cycles of amplification for $15 \mathrm{sec}$ at $95^{\circ} \mathrm{C}$ and $1 \mathrm{~min}$ at $60^{\circ} \mathrm{C}$. The expression of $\beta$-actin gene was used as an internal standard. Relative gene expression was calculated by determining the ratio between the amount of the PCR product of 5-FU metabolic and relative enzyme gene and B-actin gene.

Immunohistochemistry. All tissues from a total of 17 cases of OSCC were fixed in $10 \%$ formalin and embedded in paraffin wax. Sections, $3-\mu \mathrm{m}$ thick, were cut and mounted on aminopropyltriethoxy silane-coated slides. Sections were deparaffinized with xylene and rehydrated in graded ethanol. Endogenous peroxidase activity was quenched with $0.3 \%$ hydrogen peroxide in methanol for $20 \mathrm{~min}$ at room temperature. Proteolytic enzyme pretreatments were performed by means of $0.002 \%$ proteinase K (Roche Diagnostics, Indianapolis, IN, USA) in $50 \mathrm{mM}$ Tris-buffered saline, $\mathrm{pH} 7.6$ at room temperature for $15 \mathrm{~min}$ and $0.2 \%$ trypsin (Type 1, Sigma, St. Louis, MO, USA) in $10 \mathrm{mM}$ phosphate-buffered saline (PBS), pH 7.2 at $37^{\circ} \mathrm{C}$ for $30 \mathrm{~min}$. The sections were incubated in polyclonal antibody (diluted at 1:1,000, Taiho Pharmaceutical, Saitama, Japan) against TS and DPD overnight at room temperature. The specificity of these antibodies has been shown previously $(10,11)$. After rinsing in PBS, $\mathrm{pH} 7.2$, the sections were incubated with the universal immunoperoxidase polymer, anti-mouse and -rabbit (Histofine ${ }^{\circledR}$ Simple Stain MAX PO, Nichirei, Tokyo, Japan) at room temperature for $30 \mathrm{~min}$. The reaction products were visualized in $50 \mathrm{mM}$
Table I. The clinicopathological features of 17 OSCC patients.

\begin{tabular}{|c|c|c|c|}
\hline & \multicolumn{2}{|c|}{ Neoadjuvant therapy } & \multirow[b]{2}{*}{$\begin{array}{l}\text { Total } \\
(n=17)\end{array}$} \\
\hline & $\begin{array}{c}\mathrm{UFT}+\mathrm{RT} \\
(\mathrm{n}=10)\end{array}$ & $\begin{array}{l}\text { None } \\
(n=7)\end{array}$ & \\
\hline \multicolumn{4}{|l|}{ Gender } \\
\hline Male & 5 & 1 & 6 \\
\hline Female & 5 & 6 & 11 \\
\hline Age (average) & $68.4 \pm 11.9$ & $65.8 \pm 13.3$ & $67.4 \pm 12.2$ \\
\hline \multicolumn{4}{|l|}{ Tumor size } \\
\hline $\mathrm{T} 1$ & 0 & 3 & 3 \\
\hline $\mathrm{T} 2$ & 5 & 4 & 9 \\
\hline T3 & 0 & 0 & 0 \\
\hline $\mathrm{T} 4$ & 5 & 0 & 5 \\
\hline \multicolumn{4}{|l|}{ Nodal status } \\
\hline No & 6 & 7 & 13 \\
\hline N1 & 3 & 0 & 3 \\
\hline $\mathrm{N} 2$ & 1 & 0 & 1 \\
\hline \multicolumn{4}{|l|}{ Stage } \\
\hline 1 & 0 & 3 & 3 \\
\hline 2 & 2 & 4 & 6 \\
\hline 3 & 3 & 0 & 3 \\
\hline 4 & 5 & 0 & 5 \\
\hline \multicolumn{4}{|l|}{$\begin{array}{l}\text { Tumor } \\
\text { differentiation }\end{array}$} \\
\hline Well & 8 & 7 & 15 \\
\hline Moderate & 2 & 0 & 2 \\
\hline \multicolumn{4}{|l|}{$\begin{array}{l}\text { Anneroth's } \\
\text { classification }\end{array}$} \\
\hline 1 & 0 & 2 & 2 \\
\hline 2 & 8 & 4 & 12 \\
\hline 3 & 2 & 1 & 3 \\
\hline \multicolumn{4}{|l|}{ Tumor site } \\
\hline Tongue & 1 & 4 & 5 \\
\hline Lower gum & 5 & 0 & 5 \\
\hline Floor of mouth & 2 & 2 & 4 \\
\hline Buccal mucosa & 2 & 1 & 3 \\
\hline
\end{tabular}

Tris- $\mathrm{HCl}$ buffer, $\mathrm{pH} 7.6$, containing $50 \mathrm{mg} / \mathrm{dl}$ diaminobenzidine tetrahydrochloride and $0.006 \%$ hydrogen peroxide. The nuclei were lightly counterstained with Mayer's hematoxylin. Paraffin sections of human colon cancer tissue (cell line DLD-1/FdUrd) with high TS expression, implanted in a nude mouse, were used as a positive control. Paraffin sections of human pancreatic cancer tissue (cell line MIAPaCa-2) with high DPD expression, implanted in a nude mouse, were used as a positive control. For the negative control purpose, the primary antibody was replaced by PBS.

Evaluation of immunohistochemical staining. All of the immunostained sections under the appropriate antigen retrieval condition were reviewed by two investigators (M.T. and T.Y.) and the TS and DPD expression was divided according to the method of Sinicrope et al (12). Briefly, immunostaining was 
Table II. Sequence of real-time quantitive RT-PCR primers and sequence-specific probes for target genes.

\begin{tabular}{lll}
\hline Target gene & & \multicolumn{1}{c}{ Sequence } \\
\hline TS & Sense primer & ATTTACCTGAATCACATCGAGCC \\
& Antisense primer & TCGAAGAATCCTGAGCTTTGG \\
& TaqMan probe & FAM-AAAATTCAGCTTCAGCGAGAACCCAGACC-TAMRA \\
Sense primer & TCCCCAAAAGGCCTATTCCT \\
& Antisense primer & FAM-CCATCAAGCACCAAATGTTCC \\
& TaqMan probe & GAGTCTATTCCTGGATTCAATGTCATC \\
TP & Sense primer & CCCACGATACAGCAGCCC \\
& Antisense primer & FAM-CAGATGCAAGTGCTGCTGGACCAGG-TAMRA \\
& TaqMan probe & ACTACACTAGAGCAGCGGTTAGAATG \\
OPRT & AACTGAACTCACTGCAG-TAMRA \\
& Antisense primer & FAM-TTCTGGCTCCCGAGTAAGCATGAAACC-TAMRA \\
& TaqMan probe &
\end{tabular}

The probe were labeled with a recepter dye (FAM) situated at the 5 end of the oligonucleotide and a Quencer dye (TAMRA) located at the 3 end.

Table III. mRNA of 5-FU metabolic and relative enzymes in 17 OSCC patients and neoadjuvant therapy.

\begin{tabular}{|c|c|c|c|c|c|c|c|c|}
\hline \multirow[b]{2}{*}{ Neoadjuvant therapy } & \multicolumn{8}{|c|}{ mRNA of 5-FU metabolic and relative enzymes } \\
\hline & $\mathrm{TS}$ & P-value & DPD & P-value & OPRT & $\mathrm{P}$-value & $\mathrm{TP}$ & $P$ P-value \\
\hline Non-therapy $(n=7)$ & $15.4 \pm 17.8$ & & $25.8 \pm 38.7$ & & $55.3 \pm 69.9$ & & $308.8 \pm 369.5$ & \\
\hline $\mathrm{UFT}+\mathrm{RT}(\mathrm{n}=10)$ & $10.8 \pm 12.3$ & $\mathrm{P}=0.922$ & $25.7 \pm 27.2$ & $\mathrm{P}=0.845$ & $62.0 \pm 60.1$ & $\mathrm{P}=0.558$ & $337.2 \pm 533.2$ & $P=0.696$ \\
\hline
\end{tabular}

Table IV. Immunohistochemical staining score of TS and DPD in 17 OSCC patients.

\begin{tabular}{lcccc}
\hline & \multicolumn{4}{c}{$\begin{array}{c}\text { Immunohistochemical staining } \\
\text { score of TS and DPD }\end{array}$} \\
\cline { 2 - 5 } Neoadjuvant therapy & TS & P-value & DPD & P-value \\
\hline Non-therapy $(\mathrm{n}=7)$ & $5.7 \pm 5.9$ & & $3.1 \pm 2.1$ & \\
& & $\mathrm{P}=0.880$ & & $\mathrm{P}=0.918$ \\
UFT + RT $(\mathrm{n}=10)$ & $3.9 \pm 3.8$ & & $6.0 \pm 3.6$ & \\
\hline
\end{tabular}

expressed as the percentage of stained cells out of total number of tumor cells and assigned to one of five categories: $0,<5 \%$; $1,5-25 \% ; 2,25-50 \% ; 3,50-75 \%$ and $4,>75 \%$. The intensity of immunostaining was scored as: 1 weak; 2 moderate; 3 intense (Fig. 1). The two scores were multiplied and the product was defined as immunohistochemical score. The assessment of immunostaining was done without knowing results of other experiments.

Statistical analysis. The clinicopathological features, the mRNA levels/immunohistochemical staining score and neoadjuvant therapy were compared using the Mann-Whitney $\mathrm{U}$ test and Kruskal-Wallis test. UFT off period and mRNA expression of 5-FU metabolic and relative enzymes in neoadjuvant therapy group were compared using Spearman's correlation coefficient by rank. Statistical significance was established at the $\mathrm{P}<0.05$ level for each analysis.

\section{Results}

Effect of neoadjuvant therapy on the 5-FU metabolic and relative enzymes. We analyzed the effect of neoadjuvant therapy on the 5-FU metabolic and relative enzymes in OSCC patients by real-time quantitative RT-PCR and immunohistochemical analysis. The mRNA expression of TS, DPD, OPRT and TP was analyzed by the real-time quantitative RT-PCR using the tumor tissues treated by adjuvant therapy or none. The mean values of these mRNA expressions are summarized in Table III. The mRNA expression levels of all enzymes indicated that there was no significant difference between neoadjuvant therapy and non-neoadjuvant therapy group (Table III).

To confirm this phenomenon, immunohistochemical staining of TS and DPD was carried out using the same specimens of mRNA analysis. The mean values of TS and DPD staining scores of tumor tissues are summarized in Table IV. The staining score of TS in neoadjuvant therapy group showed a tendency of lower score as compared with that in adjuvant therapy group, but no significant difference was observed. Furthermore, the mean value of DPD staining 
A

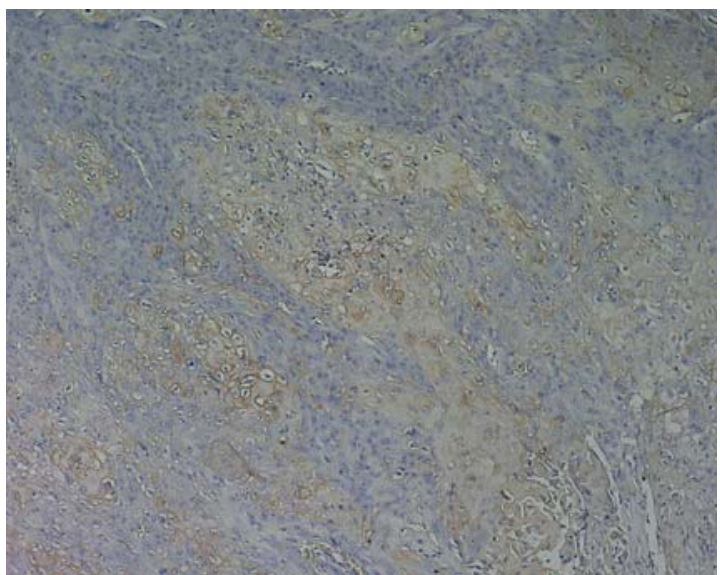

C

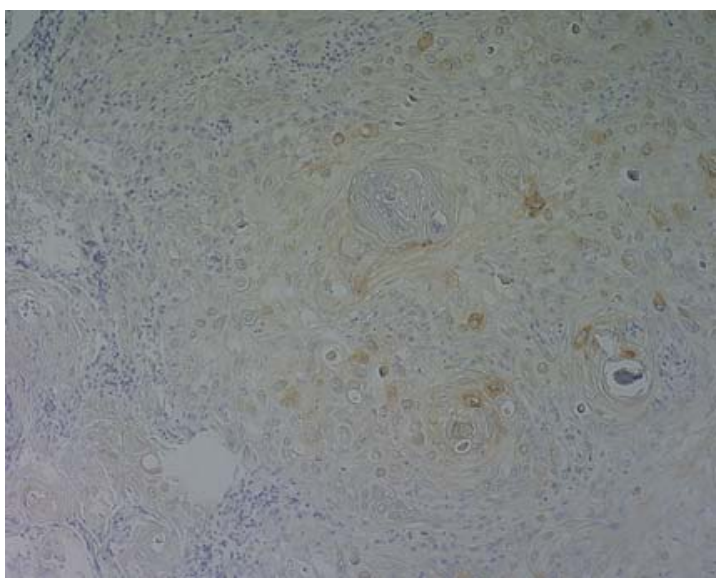

B

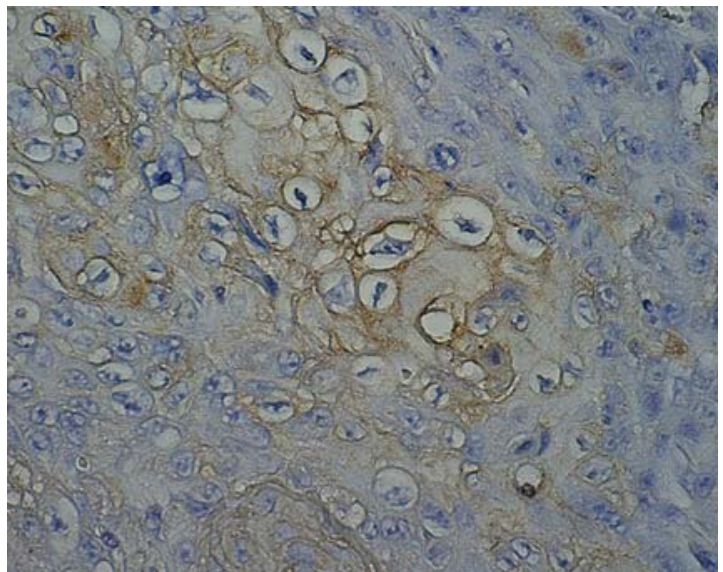

D

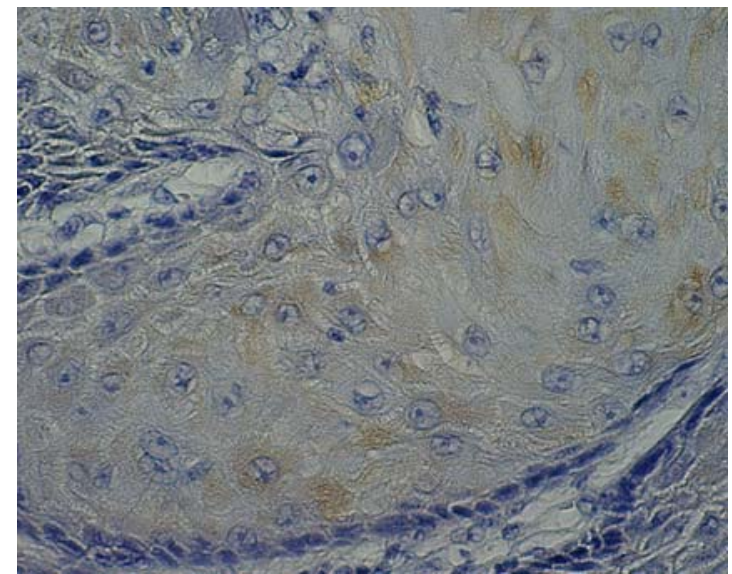

Figure 1. Photomicrographs showing representative areas of category 3, where $70 \%$ of tumor cells exhibit intense positive reactions for DPD (A, x100) (B, $\mathrm{x} 400$ ) and category 2 , where $\sim 45 \%$ of tumor cells exhibit moderate positive reactions for TS (C, x100) (B, x400) in well differentiated squamous cell carcinomas.

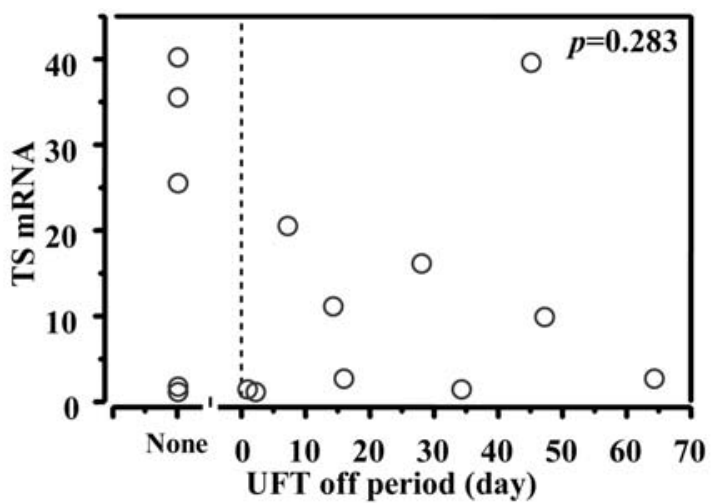

Figure 2. UFT off period and TS mRNA level in neoadjuvant therapy group and non-treated group.

scores in neoadjuvant therapy group was higher than that of adjuvant therapy group, but not statistically significant. Although immunohistological staining status did not completely correspond to the results of mRNA expression, no significant difference between groups was observed in the analyzed enzymes (Table IV).
Effects of UFT administration period on the mRNA expression of the 5-FU metabolizing enzymes. To assess the effect of UFT on the mRNA expression of the 5-FU metabolizing enzymes, we analyzed the relationship between the off period of UFT until tumor excision and mRNA expression levels of TS, DPD, OPRT and TP in neoadjuvant therapy group.

The mRNA expression of TS showed a decreasing tendency according to the days following 5-FU interruption and an increasing tendency was observed in the expression of DPD and OPRT enzymes, though P-value of TS, DPD and OPRT was 0.2830 .252 and 0.223 , respectively (Figs. 2, 3 and 4). Furthermore, the expression of TP was not affected by the off period of UFT until tumor excision (Fig. 5).

\section{Discussion}

The effects of 5-FU are closely related to the activity of its metabolic and associated enzymes of patients. 5-FU metabolic enzymes such as thymidylate synthase (TS), dihydropyrimidine dehydrogenase (DPD), orotate phosphoribosyl transferase (OPRT) and thymidine phosphorylase (TP) were extensively explored in various cancers, but have rarely been examined in OSCCs. 5-FU is metabolized into two different active 


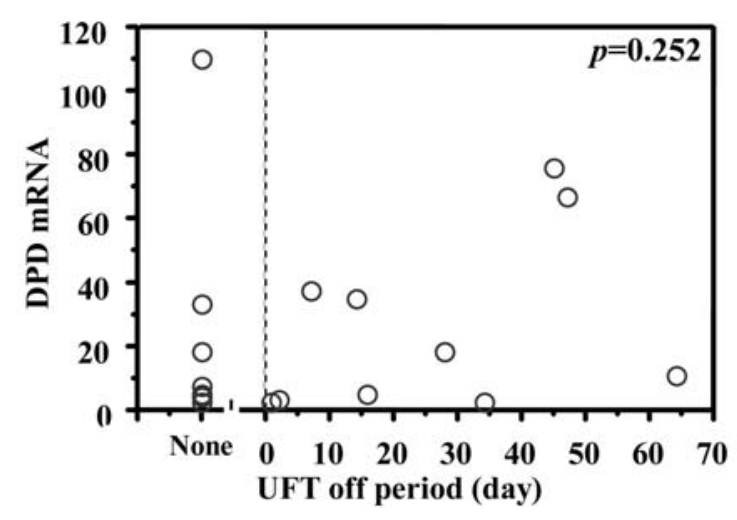

Figure 3. UFT off period and DPD mRNA level in neoadjuvant therapy group and non-treated group.

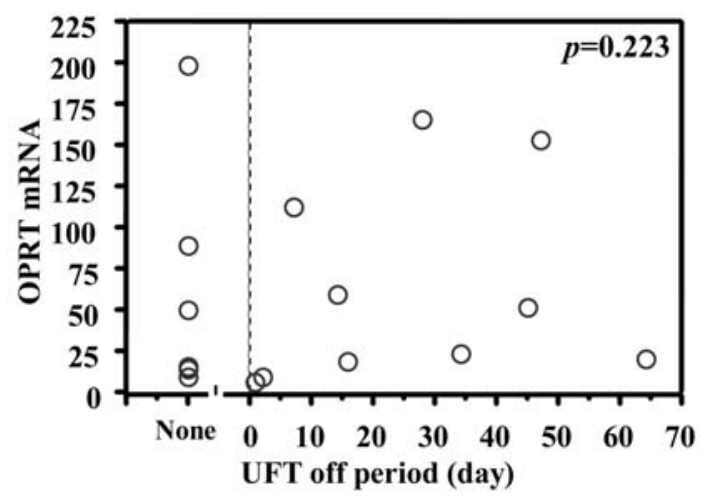

Figure 4. UFT off period and OPRT mRNA level in neoadjuvant therapy group and non-treated group.

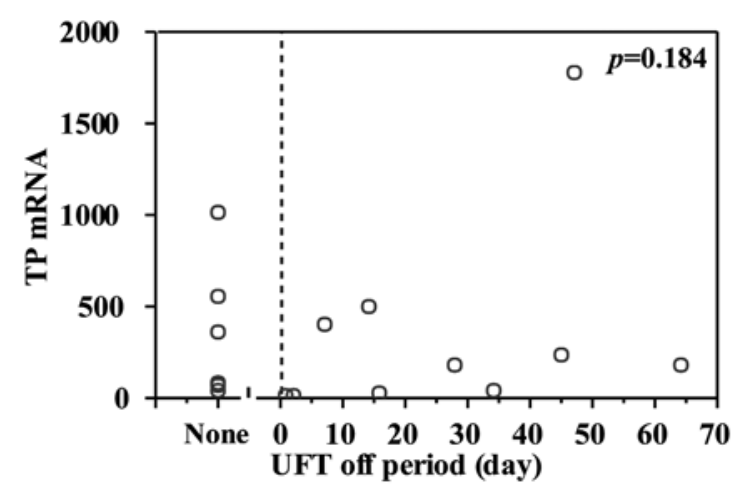

Figure 5. UFT off period and TP mRNA level in neoadjuvant therapy group and non-treated group.

forms of 5-fluorodeoxyuridine monophosphate (FdUMP) and 5-fluorouridine (FUTP) and these metabolites inhibit the DNA synthesis and RNA function, respectively. FdUMP and the coenzyme 5,10-methylene terahydrofolate form the covalent ternary complex with the DNA synthesizing enzyme thymidine synthetase (TS) (13). This complex inhibits the conversion of dUMP to dTMP that is an essential step of DNA synthesis and acts on the anti-cancer effects (14). Consequently, overexpression of TS possibly decreases the inhibitory effect of 5-FU on the DNA synthesis and several studies suggested that high amount of TS in tumor cells

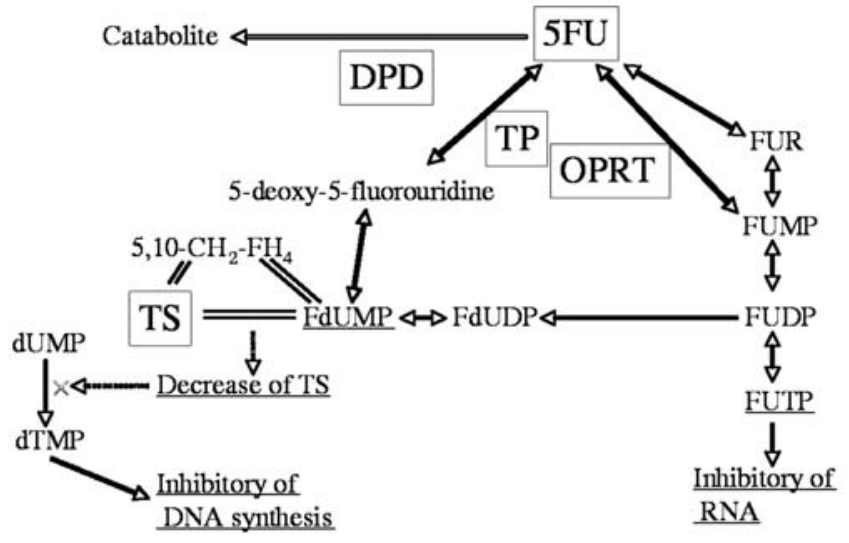

Figure 6. The metabolic pathway of 5-FU. FdUDP, 5-fluorodeoxyuridine diphosphate; FdUMP, 5-fluorodeoxyuridine monophosphate; FUDP, 5-fluorodeoxyuridine; FUMP, 5-fluorouridine monophosphate; FUTP, 5-fluorouridine triphosphate; FUR, 5-fluorouridine; dTMP, deoxythymidine monophosphate; dUMP, deoxyuridine monophosphate; DPD, dihydropyrimidine dehydrogenase; OPRT, orotate phosphoribosyl transferase; TP, thymidine phosphorylase; TS, thymidine synthase.

might decrease the efficiency of 5-FU and lead to drug resistance $(1,5,15-17)$. DPD is the initial and rate-limiting enzyme in the catabolic pathway of 5-FU. Therefore, DPD in tumor cells may reduce the anti-cancer effects of 5-FU and several studies have reported that the level of DPD expression is well correlated to the resistance of 5-FU efficiency $(3,4,18)$. OPRT is the first key enzyme for phosphorylation of 5-FU and converts 5-FU to 5-fluorouridine-5monophosphate (FUMP) and is considered to inhibit predominantly the RNA function. Thus, it is reported that high amount of intratumoral OPRT correlates well to the tumor sensitivity to 5 -FU $(2,19,20)$. TP is an enzyme that catalyzes the conversion of 5-FU to 5-deoxy-5-fluorouridine reversibly and high expression of this enzyme in a tumor is correlated with high response rate to 5-deoxy-5-fluorouridine $(21,22)$ (Fig. 6).

As described above, 5-FU was metabolized and modified its anti-cancer effects by these enzymes. Therefore, evaluation of these enzyme expression levels can be used to determine the desirable efficiency and prognosis including the prevention of 5-FU side effects prospectively. From this point of view, the relationship between enzyme expression and anti-cancer effect was examined by many researchers. Although all results are not completely in agreement, previous studies indicated that the low expression of TS and DPD possibly enhanced the anti-cancer effects of 5-FU by analyzing the mRNA level and immunohistochemical staining of OSCC cases $(1,3-5,23)$. Furthermore, the high expression of OPRT mRNA may prognosticate the good efficiency of 5-FU (2). However, effects of neoadjuvant therapy on the 5-FU metabolic and relative enzymes remain unclear. It was revealed that the exposure of cells to 5-FU increased the expression of TS in vitro $(9,24-26)$ and several clinical studies demonstrated that the neoadjuvant therapy might affect the 5-FU metabolic and relative enzyme status. A previous study indicated that a significant increase of DPD and no change of TS were observed in colorectal and gastric cancer (27) and that no change of DPD and TS was observed 
in gastric cancer (8) following 5-FU and cisplatin-based chemotherapy. Other studies reported that radiation therapy did not affect the DPD expression in rectal cancer (6) and that neoadjuvant therapy using $5-\mathrm{FU}$, cisplatin and radiation therapy decreased the expression of TS and DPD in esophageal cancer (28). These results suggest that the possibility of modifying effect of neoadjuvant therapy on the 5-FU metabolizing enzyme status, though these results are not identical and the effects of neoadjuvant therapy may be variable in different organs and the gene expression of relative enzymes would depend on the metabolism of 5-FU in a particular organ site. Additional study is needed to determine whether different type of cancer respond similarly or differently to 5-FU-based therapy and/or radiation. Radiation therapy and/or chemotherapy using 5-FU are commonly used and bring the desirable prognosis in the treatment of oral cancer, though the effect of neoadjuvant therapy on the 5-FU metabolizing enzyme status is not yet fully examined.

Our results of mRNA analysis indicated that mRNA expression of TS, DPD, OPRT and TP were not significantly affected by the neoadjuvant therapy using 5-FU and irradiation and similar results using the same specimens were observed in the immunohistochemical analysis of TS and DPD, two key enzymes in the 5-FU metabolism, though immunohistological staining status did not correspond to the results of mRNA analysis completely. Furthermore, as a comparison of the 5-FU administration period with mRNA expression of these enzymes, neoadjuvant therapy did not affect the mRNA expression of 5-FU metabolizing enzymes. These results suggested that the expression status of these enzymes would not be affected by 5-FU-based chemotherapy and radiation received before surgical treatment and the surgical tumor tissues may serve as a useful specimen source to analyze 5-FU metabolic enzymes expression for the evaluation of 5-FUbased adjuvant chemotherapy efficiency following surgery. Comprehensive studies with larger sample size are needed to further clarify the efficacy of neoadjuvant therapy using 5-FU and radiation and the gene and protein expression levels of 5-FU metabolic enzymes in oral cancer. Furthermore, quantitative RT-PCR and immunohistochemical staining are simple and quick methods, and these techniques could be used to assess the 5-FU metabolic enzyme levels in patients treated with 5-FU-based chemotherapy or non-treated group in order to determine the prospective efficacy of 5-FU therapy, though we observed a discrepancy of enzyme expression status between mRNA quantification and immunohistochemical staining status. Therefore, both mRNA quantification and immunohistochemical staining is recommended for the evaluation of the 5-FU metabolizing enzymes.

As a conclusion, the results of this study suggested that the neoadjuvant therapy of OSCC might not affect the expression status of 5-FU metabolic and relative enzymes in surgical tumor samples and the tumor tissues might serve as a useful specimen source to analyze the expression status of the 5-FU metabolic and relative enzymes and to determine the prospective efficiency of 5-FU-based adjuvant chemotherapy.

\section{Acknowledgments}

We thank Taiho Pharmaceutical Co. Ltd. for its kind providing polyclonal antibodies to TS and DPD.

\section{References}

1. Harada K, Kawashima Y, Yoshida H and Sato M: Thymidylate synthase expression in oral squamous cell carcinoma predicts response to S-1. Oncol Rep 15: 1417-1423, 2006.

2. Yoshitomi I, Kawasaki G, Yanamoto S and Mizuno A: Orotate phosphoribosil transferase mRNA expression in oral squamous cell carcinoma and its relationship with the dihydropyrimidine dehydrogenase expression and the clinical effect of 5-fluorouracil. Oral Oncol 42: 880-887, 2006.

3. Hoque M, Kawamata H, Nakashiro K, et al: Dihydropyrimidine dehydrogenase mRNA level correlates with the response to 5fluorouracil-based chemo-immuno-radiation therapy in human oral squamous cell cancer. Int J Oncol 19: 953-958, 2001.

4. Kobayashi H, Koike T, Nakatsuka A, et al: Dihydropyrimidine dehydrogenase expression predicts survival outcome and chemosensitivity to 5-fluorouracil in patients with oral squamous cell carcinoma. Oral Oncol 41: 38-47, 2005.

5. Kawano K, Goto H, Kanda T and Yanagisawa S: Predictive value of immunohistochemical thymidylate synthase expression for histological response to Tegafur/Uracil (UFT) in oral squamous cell carcinoma. Int J Oral Maxillofac Surg 32: 633-637, 2003.

6. Komuro Y, Watanabe T, Tsuno N, et al: The usefulness of immunohistochemical evaluation of dihydropyrimidine dehydrogenase for rectal cancer treated with preoperative radiotherapy. Hepatogastroenterology 50: 906-911, 2003.

7. Inoue T, Segawa T, Shiraishi T, et al: High-grade and hormonetreated prostate cancer express high levels of thymidylate synthase. BJU Int 98: 197-200, 2006.

8. Fukuda H, Takiguchi N, Koda K, Oda K, Seike K and Miyazaki M: Thymidylate synthase and dihydropyrimidine dehydrogenase are related to histological effects of 5-fluorouracil and cisplatin neoadjuvant chemotherapy for primary gastric cancer patients. Cancer Invest 24: 235-241, 2005.

9. Miyazaki K, Shibahara T, Sato D, et al: Influence of chemotherapeutic agents and cytokines on the expression of 5fluorouracil-associated enzymes in human colon cancer cell lines. J Gastroenterol 41: 140-150, 2006.

10. Okabe H, Arakawa K, Takechi T and Fukushima M: Expression of recombinant human dihydropyrimidine dehydrogenase and its application to the preparation of anti-DPD antibodies for immunochemical detection. Gan to Kagaku Ryoho 27: 891-898, 2000.

11. Takenoue T, Kitayama J, Takei Y, et al: Characterization of dihydropyrimidine dehydrogenase on immunohistochemistry in colon carcinoma, and correlation between immunohistochemical score and protein level or messenger RNA expression. Ann Oncol 11: 273-279, 2000.

12. Sinicrope FA, Rusan SB, Cleary KR, Stephens LC, Lee JJ and Levin B: BCL-2 and p53 oncoprotein expression during colorectal tumorigenesis. Cancer Res 55: 237-241, 1995.

13. Danenberg PV: Thymidylate synthase - a target enzyme in cancer chemotherapy. Biochem Biophys Acta 473: 73-92, 1977.

14. Santi DV, MacHenry CS and Sommer H: Mechanism of interaction of thymidylate synthas with 5-fluorodeoxyuridylate. Biochemistry 13: 471-481, 1974.

15. Leichman CG, Lenz HJ, Leichman L, et al: Quantitation of intratumoral thymidylate synthase expression predicts for disseminated colorectal cancer response and resistance to protracted-infusion fluorouracil and weekly leucovorin. J Clin Oncol 15: 3223-3229, 1997.

16. Beck A, Etienne MC, Cheradame S, et al: A role for dihydropyrimidine dehydrogenase and thymidylate synthase in tumor sensitivity to fluorouracil. Eur J Cancer 30: 1517-1522, 1994

17. Lenz HJ, Leichman CG, Danenberg KD, et al: Thymidylate synthase mRNA level in adenocarcinoma of the stomach: a predictor for primary tumor response and overall survival. J Clin Oncol 14: 176-182, 1996.

18. Etienne MC, Cheradame S, Fischel JL, et al: Response to fluorouracil therapy in cancer patients: the role of tumoral dihydropyrimidine dehydrogenase activity. J Clin Oncol 13: 1663-1670, 1995. 
19. Peters GJ, Laurensse E, Leyva A, Lankelma J and Pinedo HM: Sensitivity of human, murine, and rat cells to 5-fluorouracil and 5-deoxy-5-fluorouridine in relation to drug-metabolizing enzymes. Cancer Res 46: 20-28, 1986.

20. Peters GJ, Braakhuis BJ, de Brujin EA, Laurensse EJ, van Walsum M and Pinedo HM: Enhanced therapeutic efficacy of 5-deoxy-5fluorouridine in 5-fluorouracil-resistant head and neck tumors in relation to 5-fluorouracil metabolizing enzymes. Br J Cancer 56: 327-334, 1989

21. Koizumi W, Saigenji K, Nakamaru N, Okayasu I and Kurihara M Prediction of response to 5-deoxy-5fluorouridine (5-DFUR) in patients with inoperable advanced gastric cancer by immunostainning of thymidine phosphorylase/palatelet-derived endothelial cell growth factor. Oncology 56: 215-222, 1999.

22. Sawada N, Ishikawa T, Fukase Y, Nishida M, Yoshikubo T and Ishitsuka $\mathrm{H}$ : Induction of thymidine phosphorylase activity and enhancement of capecitabine efficacy by taxol/taxotere in human cancer xenografts. Clin Cancer Res 4: 1013-1019, 1998.

23. Kawasaki G, Yoshitomi I, Yamamoto S and Mizuno A: Thymidylate synthase and dihydropyrimidine dehydrogenase expression in oral squamous cell carcinoma: An immunohistochemical and clinicopathologic study. Oral Surg Oral Med Oral Pathol 94: 717-723, 2002.
24. Berger SH, Jenh $\mathrm{CH}$, Johnson LF and Berger FG: Thymidylate synthase overproduction and gene amplification in fluorodeoxyuridineresistant human cells. Mol Pharmacol 28: 461-467, 1985.

25. Kirihara Y, Yamamoto W, Toge and Nishiyama M: Dihydropyrimidine dehydrogenase multidrug resistance-associated protein, and thymidylate synthase gene expression levels can predict 5 -fluorouracil resistance in human gastrointestinal cancer cells. Int J Oncol 14: 551-556, 1999.

26. Washtien WL: Increased levels of thymidylate synthetase in cells exposed to 5-fluorouracil. Mol Pharmacol 25: 171-177, 1984.

27. Uchida K, Hayashi K, Kuramochi H and Takasaki K: Changes in intratumoral thymidylate synthase (TS) and dihydropyrimidine dehydrogenase (DPD) mRNA expression in colorectal and gastric cancer during continuous tegafur infusion. Int J Oncol 19: 341-346, 2001

28. Schneider S, Uchida K, Brabender J, et al: Downregulation of TS, DPD, ERCC1, GST-Pi, EGFR, and HER2 gene expression after neoadjuvant three-modality treatment in patients with esophageal cancer. J Am Coll Surg 200: 336-344, 2005. 